\title{
Three-dimensional echocardiography in adult congenital heart disease
}

\author{
Hyun Suk Yang
}

Division of Cardiovascular Medicine, Department of Internal Medicine, Konkuk University School of Medicine, Seoul, Korea

Received: July 31, 2016

Accepted: June 16, 2017

\section{Correspondence to \\ Hyun Suk Yang, M.D.}

Division of Cardiovascular Medicine, Department of Internal Medicine, Konkuk University Medical Center, 120-1 Neungdong-ro, Gwangjin-gu, Seoul 05030, Korea

Tel: +82-2-2030-7519

Fax: +82-2-2030-7748

E-mail: yang.hyun@kuh.ac.kr
Congenital heart disease (CHD) is now more common in adults than in children due to improvements in fetal echo, neonatal and pediatric care, and surgical techniques leading to dramatically increased survivability into adulthood. Adult patients with CHD, regardless of prior cardiac surgery, experience further cardiac problems or therapeutic challenges; therefore, a non-invasive, easily accessible echocardiographic examination is an essential follow-up tool. Among echocardiographic modalities, three-dimensional (3D) echocardiography provides better delineation of spatial relationships in complex cardiac geometries and more accurate volumetric information without geometric assumptions. For atrial septal defects, an en face view of the tissue defect allows better decisions on device closure. For tricuspid valve malformations, an en face view provides diagnostic information that is difficult to obtain from routine $2 \mathrm{D}$ tomography. In repaired tetralogy of fallot with pulmonary regurgitation, preoperative $3 \mathrm{D}$ echocardiography-based right ventricular volume may be used to determine the timing of a pulmonary valve replacement in conjunction with cardiovascular magnetic imaging. For optimal adult CHD care, 3D echocardiography is an important complement to routine $2 \mathrm{D}$ echocardiography.

Keywords: Echocardiography, three-dimensional; Heart defects, congenital

\section{INTRODUCTION}

\section{History of three-dimensional echocardiography}

From a historical perspective, three-dimensional (3D) echocardiography was applied clinically after the development of real-time or 'live' 3D echocardiography. Real-time 3D echocardiography has existed since 1990 with sparse-array transducers [1]; however, it was not actually performed in real time, requiring a slow rotation of ultrasound probes and complicated processing with relatively low spatial resolution. Since 2000 , with fully sampled, higher-resolution matrix-array transducers and the software and hardware to process the information, real-time $3 \mathrm{D}$ transthoracic echocardiography (TTE) has been clinically applicable $[2,3]$. Since 2007 , real-time
3D transesophageal echocardiography (TEE) has been performed regularly (Fig. 1) [4-7]. In 2004, we had an opportunity to work with early leading $3 \mathrm{D}$ TTE groups at the University of Chicago Medical Center under Professor Roberto Lang and the Mayo Clinic under Professor Jae K. Oh [3,5], and in 2007 we were exposed to the initial model of real-time 3D TEE at the Mayo Clinic in Scottsdale, AZ, under Professor Krishnaswamy Chandrasekaran [6]. Since the late 2000s, real-time 3D T'TE and TEE have been evolving in both imaging hardware and analysis software, yielding higher temporal resolution, larger sector angles, and even single-beat, real-time $3 \mathrm{D}$ color Doppler. In South Korea, the majority of referral medical centers are capable of real-time $3 \mathrm{D}$ echocardiography in their daily clinical practice. 


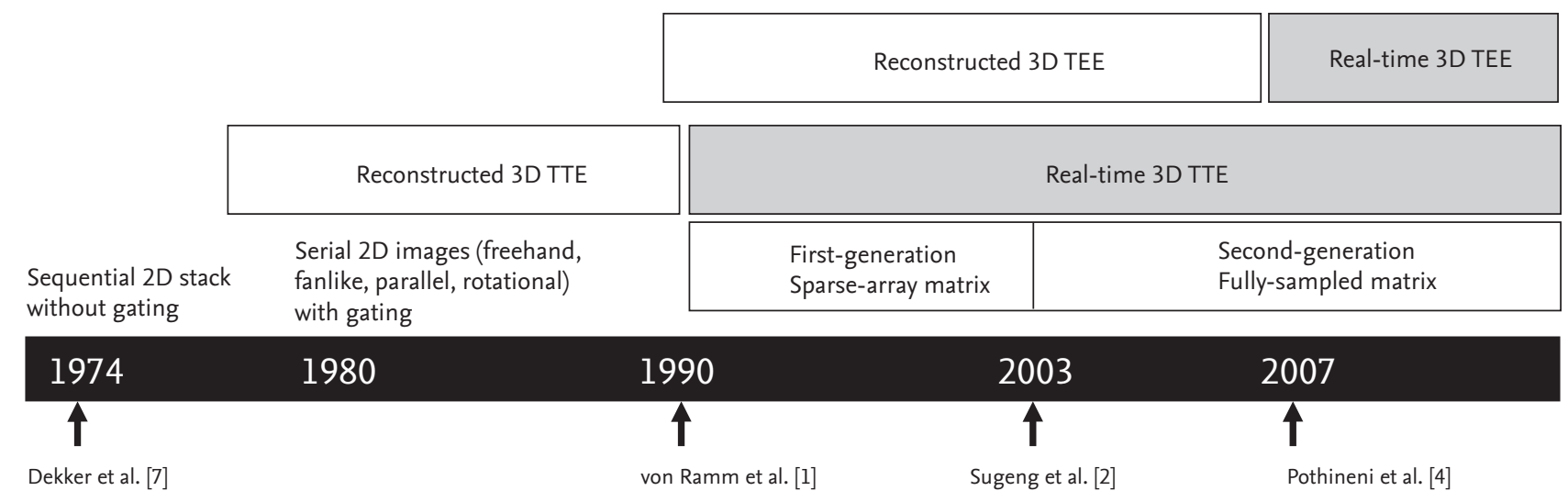

Figure 1. Historical perspective of three-dimensional $(3 \mathrm{D})$ transthoracic echocardiography (TTE) and ${ }_{3} \mathrm{D}$ transesophageal echocardiography (TEE).

\section{Role of 3D echocardiography in congenital heart disease}

Among the clinical applications of real-time $3 \mathrm{D}$ echocardiography, that in congenital heart disease (CHD) is promising due to unique projections from the living complex anatomy (such as en face views), true volumetric quantification without geometric assumptions (especially important for complex right ventricle $[\mathrm{RV}]$ or functional single ventricle [FSV] assessment), and live dynamic geometric guidance during the interventional procedures [5]. Multidetector computed tomographic (MDCT) imaging or cardiovascular magnetic resonance imaging (CMR) may provide better image resolution and ventricular volume assessment in patients with adult CHD, but the former is limited due to radiation exposure or contrast agents and the latter due to intracardiac devices or coils related to prior CHD interventions or surgeries. Moreover, in contrast to $3 \mathrm{D}$ echocardiography, MDCT and CMR require time-consuming off-line processing that is difficult to present in a dynamic, real-time environment for procedural guidance.

At this time, with its spatial and volumetric advantages, $3 \mathrm{D}$ echocardiography is an important complement to but not a replacement for routine $2 \mathrm{D}$ or Doppler echocardiography. This review discusses the applications of 3D echocardiography in adult CHD not only for de novo or unoperated congenital defects, but also for common late problems following palliative or corrective surgeries in complex congenital defects.

\section{CLINICAL PRESENTATIONS OF ADULT CON- GENITAL HEART DISEASE}

The incidence of CHD does not differ significantly between countries or over time, and was reported to be 4/1,000 live births in 1941 to 1950 [8] and 8.56/1,000 live births in 1978 [9]. Owing to advancements in fetal echocardiographic detection, neonatal and pediatric care, and surgical techniques, about $85 \%$ of children born with congenital cardiac defects survive into adulthood [10]; as a result, adults with CHD outnumber children. Thus, understanding transitional medical care from pediatric to adult internal medicine is essential, and the adult medical provider should characterize the anatomy and physiology of CHD and possible long-term complications, such as heart failure or arrhythmia.

In adults, CHD presents three disease patterns. First, de novo diagnosis of CHD, typically based on complaints of dyspnea or cardiac murmurs due to flaws such as atrial septal defects (ASD), ventricular septal defects (VSD), or patent ductus arteriosus. At this time, de novo diagnosis in adulthood is rarer due to extensive neonatal or pediatric cardiac evaluation; regardless, it is important to decide whether the defects require medical or surgical intervention, and if surgery is indicated, whether it is possible to operate without Eisenmenger syndrome. The second pattern involves patients with a childhood diagnosis without surgical intervention (mostly due to mild CHD) such as small and asymptomatic ASD, VSD, or bicuspid aortic valves without significant functional 
problems, requiring only observation. The third pattern includes patients who underwent palliative or corrective surgeries during childhood and subsequently have residual lesions that require medical or surgical management in adulthood. CHD, such as ASD or VSD, after closure of the defects does not typically require medication or follow-up in adulthood. However, in cases of complex CHD, clinical and echocardiographic longitudinal follow-up is essential through adulthood: (1) after total correction of the tetralogy of Fallot (TOF), follow-up for pulmonary regurgitation or RV function in adulthood and (2) after the Fontan procedure, in patients with an FSV, surveillance imaging for possible long-term complications such as heart failure, atrioventricular valve regurgitation, intracardiac thrombi, or cardiac arrhythmias is important.

\section{OPTIMAL 3 D ECHO IMAGING TECHNIQUE IN ADULT CONGENITAL HEART DISEASE}

For clinical 3D echocardiography, commercially available real-time 3D TTE/TEE transducers and ultrasound systems (iE33 or Epiq 7, $\mathrm{X}_{3}-1$ or $\mathrm{X}_{5-1} / \mathrm{X}_{7-2 t}$, Philips Medical System, Andover, MA, USA; Vivid 7 or E9, $3 \mathrm{~V}$ or $4 \mathrm{~V} / 6 \mathrm{VT}$, GE Healthcare, Wauwatosa, WI, USA; Acuson SC2000, 4Z1c/Z6Ms, Siemens Medical Solution, Mountain View, CA, USA) have been used [11]. Several $3 \mathrm{D}$ imaging protocols have been proposed $[5,12]$, but a purpose-driven volumetric acquisition mode with a narrow-angle/high-density and a higher frame rate to maximize both axial and temporal resolution is commonly used. In addition, bi-plane or tri-plane guidance of full-volume (or single beat volume) acquisitions can be used to avoid loss of ventricular walls, leading to optimal off-line analysis of ventricular volume. In principle, a good $2 \mathrm{D}$ echo image is the foundation of a good $3 \mathrm{D}$ image, so $2 \mathrm{D}$ images should be optimized followed by 3D optimization with appropriate gain (echo "drop out" with low gain may mimic tissue defects) and compression settings. In addition, any electrocardiogram-gated, full-volume acquisition requires expertise to avoid stitching artifacts [5]. For analysis, on-cart or off-line software is chosen according to the purpose or clinical information related to the specific congenital cardiac defects: en face views for tissue defects (ASD or VSD) and atrioventricular valve regurgitation and $3 \mathrm{D}$ volumetric assessment for RV and FSV.

\section{COMMON ADULT CONGENITAL HEART DIS- EASE}

\section{Atrial septa defects}

ASDs are one of the most common adult CHDs after bicuspid aortic valves [13]. The American College of Cardiology (ACC)/American Heart Association (AHA) 2008 guidelines recommend ASD closure in patients with RV enlargement, regardless of symptoms (class I) [14]; smaller ASDs (diameter $<5 \mathrm{~mm}$ ) with no evidence of RV enlargement or pulmonary hypertension do not require closure. The only absolute contraindication for ASD closure is patients with irreversible pulmonary hypertension (pulmonary vascular resistance $>8$ Woods units) and no evidence of left-to-right shunting [14]. Routine $2 \mathrm{D}$ and Doppler echocardiographic evaluation of the defect itself (location, number, size, flow direction) and associated findings (RV size and function, pulmonary arterial systolic pressure from tricuspid regurgitation velocity, tricuspid regurgitation amount, a cleft mitral valve in primum type, anomalous pulmonary venous return in sinus venosus type) are used to decide whether to perform percutaneous or surgical closure.

In addition, 3D echocardiography has three potential roles in ASD. First, it could provide an en face view of the defect to evaluate the actual types, numbers, size, and shape (which is typically oval, not round), and determine the shortest tissue rims around the defect (Fig. 2A), which is important for multiple ASD device closures and procedural monitoring (Fig. 2B) $[15,16]$. Among the four types of ASD (secundum, primum, sinus venosus, and coronary sinus), percutaneous transcatheter device closure is feasible only in the secundum type, excluding large defects (> $38 \mathrm{~mm}$ diameter) or insufficient (< $5 \mathrm{~mm}$ ) septal rims; however, a deficient retroaortic rim (anterior rim) is not a contraindication to device closure, requiring careful consideration [17]. Second, 3 D echocardiography may provide a better determination of cleft mitral valve in patients with the primum defect (Fig. 2C). Third, it can provide volumetric information for an enlarged RV or geometric details of the dilated tricuspid annulus from the en face view (Fig. 2D), which can 

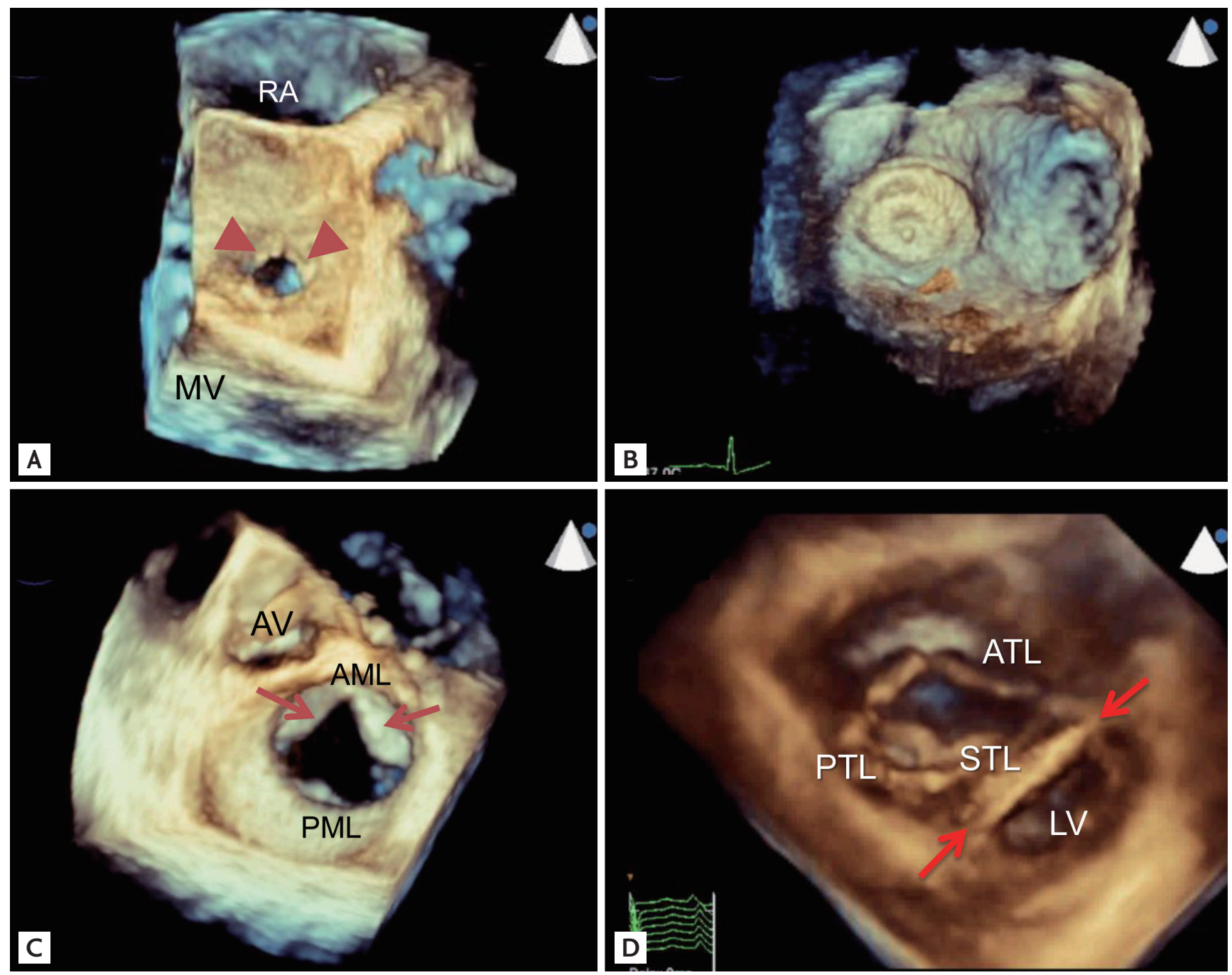

Figure 2. (A) A secundum atrial septal defect (arrowheads) from a left atrial perspective via real-time three-dimensional (3D) transesophageal echocardiography. (B) Immediately after deployment of the left-sided disc from a left atrial perspective via real-time 3D transesophageal echocardiography. (C) An en face view of the mitral valve from the left atrial perspective reveals a cleft mitral valve (arrows) in a 40-year-old woman with a repaired partial endocardial cushion defect. (D) An en face view of the tricuspid valve and dilated tricuspid annulus from an atrial perspective by full-volume-dataset rendered 3D transthoracic echocardiography. The inter-ventricular septum (arrows) is flattened, which makes the left ventricle (LV) D-shaped. RA, right atrial cavity; MV, mitral valvet; AML, anterior mitral leaflet; PML, posterior mitral leaflet; AV, aortic valve; ATL, anterior tricuspid leaflet; PTL, posterior tricuspid leaflet; STL, septal tricuspid leaflet.

be used for concomitant tricuspid annuloplasty during ASD patch closure. The 3D-echocardiography-derived RV global and regional ejection fractions (EF) are also strongly negatively correlated with RV afterload [18].

\section{Ventricular septal defects}

Isolated VSD is the most common form of CHD. The incidence of muscular VSD has been reported to be up to $53.2 / 1,000$ live births [19], but accounts for only $10 \%$ of adult CHD since $89 \%$ of these defects close spontaneously after 1 year [19]. In contrast to complex VSD combined with complex congenital defects in pediatrics, isolated VSD diagnosed in adults is relatively simple with four anatomic types: infundibular VSD (supracristal or subarterial type), membranous VSD (conoventricular, the most common type; about 80\%), inlet defects (atrioventricular canal type), and muscular defects. Indications for VSD closure in adults include LV volume overload 
and a significant pulmonary to systemic flow ratio (Qp/ Qs $\geq 2$ ); contraindications for VSD closure include severe irreversible pulmonary arterial hypertension [13]. Routine 2D and Doppler echocardiographic evaluation of the defect (location, number, size, and flow direction or velocity) and associated findings (LV size or function, pulmonary arterial systolic pressure from VSD shunt velocity, aortic regurgitation, sinus of Valsalva dilatation, double-chambered RV) are important in evaluating and closing the defect.

Three-dimensional echocardiography has a potential diagnostic role in two ways. First, it can provide an en face VSD on the RV septal surface to assess the actual shape and size of the defect, which can be underestimated in routine $2 \mathrm{D}$ tomographic views $[20,21]$, and provide information on the relationship to surrounding structures. The appropriate anatomy of the VSD location from the tricuspid and aortic valves with an adequate rim of tissue is important in transcatheter device closure $[21,22]$. The incremental value of $3 \mathrm{D}$ echocardiography over routine $2 \mathrm{D}$ techniques has been reported based on the assessment of combined complex lesions such as a sinus of Valsalva rupture or a Gerbode defect $[23,24]$. Second, $3 \mathrm{D}$ volumetric assessment of the LV depicts the consequence of volume overload from the hemodynamically significant VSD shunt.

\section{Ebstein's anomaly}

Ebstein's anomaly is a common congenital cause of isolated tricuspid regurgitation in adults, with a prevalence of $0.72 / 10,000$ live births [24]. Accurate classification remains challenging due to substantial anatomical variations: in type A, there is inadequate RV volume; in type $\mathrm{B}$, a large atrialized RV with a mobile anterior leaflet; in type $\mathrm{C}$, restricted anterior leaflet with infundibular obstruction; and in type $\mathrm{D}$, near complete atrialization of the RV [25]. The type or severity varies with the age of presentation [26]. Adult patients with symptomatic Ebstein's are typically mild de novo diagnoses or once-severe childhood diagnoses now dealing with the remaining symptoms or arrhythmias after tricuspid valve repair. The key echocardiographic findings include exaggerated apical displacement of the tricuspid annulus $\left(\geq 8 \mathrm{~mm} / \mathrm{m}^{2}\right)$ compared with the mitral annulus in an apical four-chamber view and a dysplastic tricuspid valve with RV dysfunction. Since the tri-leaflets are non-planar, identification of individual leaflets from routine $2 \mathrm{D}$ TTE is challenging and controversial [27], as is TEE due to the far field location (the higher frequency used in TEE limits deep ultrasound penetration). Three-dimensional echocardiographic evaluation with an en face view, multi-slice or flexi-slice rotational views, or tri-plane with or without color Doppler images increased our understanding of the malformed tricuspid valve (Fig. 3) $[28,29]$ and provided additional information on the morphology and function of tricuspid valves, right ventricular outflow tracts (RVOTs), and pulmonic valves, as well as superior $\mathrm{RV}$ volumetric information [30].

\section{Repaired tetralogy of Fallot with pulmonary regur- gitation}

TOF is one of the most common cyanotic CHD with four anatomic features (VSD, overriding aorta, RVOT obstruction, and RV hypertrophy) and a prevalence of 4.7/10,000 live births [31]. Pulmonary atresia with VSD and major aorta-pulmonary collateral arteries is the most extreme variant of TOF, accounting for approximately one-fifth of such cases [32]. Most patients with TOF undergo intracardiac repair in the first year of life [33]; therefore, adult patients with TOF tend to have repaired TOF. Common chronic postoperative complications in adulthood are pulmonary regurgitation, RV enlargement, RV dysfunction, and arrhythmias [34]. Postoperative echocardiography is recommended annually until the age of 10 and every 2 years through adulthood [35] to identify any residual anatomic and hemodynamic abnormalities, assess their severity, and provide information for clinical decisions.

Multimodality imaging guidelines for patients with repaired TOF have been suggested [35]. Routine $2 \mathrm{D}$ and Doppler echocardiography are non-invasive, highly accessible techniques suitable for longitudinal follow-up of repaired TOF, but several limitations should be discussed for RV evaluation. For RV size, diameter $>42 \mathrm{~mm}$ at the basal level indicates RV enlargement [36]; unfortunately, the $2 \mathrm{D}$ tomographic image plane shows examiner dependence when comparing different planes over time, yielding inaccurate results. For RV functional analysis, a 2D-derived RV EF is not generally recommended because of the numerous geometric assumptions [36]. A 2D fractional area change (FAC) $<35 \%$ provides an estimate of RV systolic dysfunction, but not 

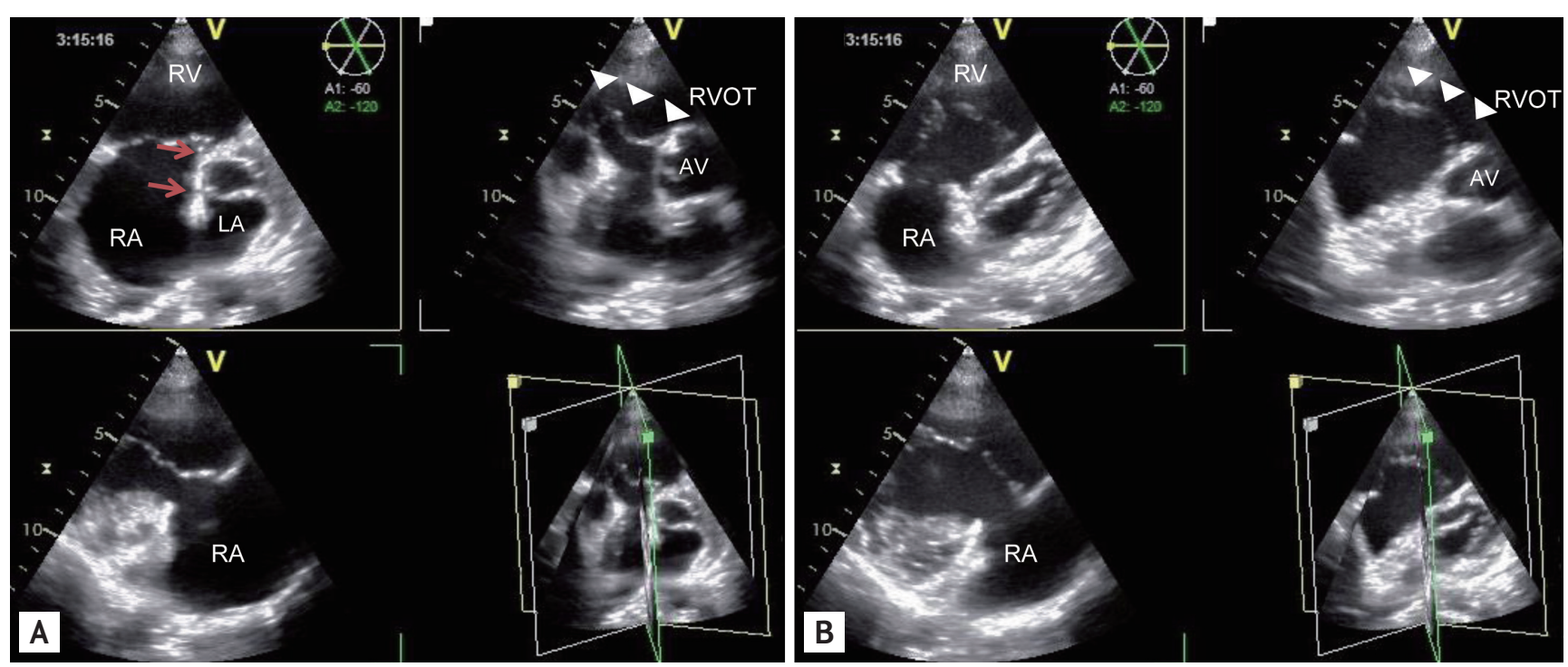

Figure 3. Tri-plane images of systolic (A) and diastolic (B) phase of the tricuspid valve in a 37-year-old woman with Ebstein's anomaly repaired in her childhood. The septal leaflet is apically displaced compared with the mitral leaflet, which was measured to be $18.8 \mathrm{~mm} / \mathrm{m}^{2}$ (between two arrows), and a large flopping anterior leaflet (arrowheads) was observed without significant right ventricular outflow obstruction. RV, right ventricle; RA, right atrium; LA, left atrium; AV, aortic valve; RVOT, right ventricular outflow tract.

all of the RV is in view. A tricuspid annular plane systolic excursion $<16 \mathrm{~mm}$ represents RV longitudinal dysfunction, but decreases after cardiac surgery despite the lack of reduction in RV FAC [37] or 3D RV EF [38]. Therefore, it is not suitable for repaired TOF patients. For serial follow-up, $3 \mathrm{D}$ volume rendered optimal $2 \mathrm{D}$ planes are preferred over $2 \mathrm{D}$ images for comparisons. In addition, 3D echocardiography can contain the entire RV (including the RVOT) and evaluate the true volumetric changes without simplifying geometric assumptions (Fig. 4). The recently developed RV strain analysis from acquired $3 \mathrm{D}$ or $4 \mathrm{D}$ datasets provides new parameters of RV regional and global function, which integrate deformation in the longitudinal, circumferential, and radial dimensions [39].

Pulmonary valve replacement (PVR) to restore pulmonary valve competence was considered to be a positive approach in a meta-analysis of 3,118 patients from 48 studies to restore RV function [40]. A single center followed 1,014 patients with repaired TOF for $7.3 \pm 6.8$ years. PVR was observed in $27.4 \%$ of patients at a mean age of $31.4 \pm 16.4$ years [41]. Guidelines from the ACC/AHA 2008 [13], Canadian Cardiology Society 2009 [42], and European Society of Cardiology 2010 [43] recommend PVR for severe pulmonary regurgitation and symptoms of decreased exercise tolerance (class I), severe pulmonary regurgitation and moderate to severe RV dysfunction or enlargement, moderate to severe tricuspid regurgitation (class IIa), and severe pulmonary regurgitation with an right ventricle end-diastolic volume index (RVEDVi) > $170 \mathrm{~mL} / \mathrm{m}^{2}$ (class IIa). The intervention timing depends on how long PVR could be delayed while attempting to restore optimal RV function.

To determine the optimal timing for PVR, several RV parameters have been proposed. Currently, CMR is the reference standard for RV quantification and the timing of PVR in repaired TOF with pulmonary regurgitation based on pre-operative CMR parameters: Therrien et al. [44] propose PVR if RVEDVi $\leq 170 \mathrm{~mL} / \mathrm{m}^{2}$ or right ventricular end-systolic volume index (RVESVi) $\leq 85 \mathrm{~mL} / \mathrm{m}^{2}$; Oosterhof et al. [45] apply RVEDVi $<160 \mathrm{~mL} / \mathrm{m}^{2}$ or RVES$\mathrm{Vi}<82 \mathrm{~mL} / \mathrm{m}^{2}$; Geva et al. [46] recommend RVESVi $<90 \mathrm{~mL} / \mathrm{m}^{2}$ since RVESVi may be more sensitive than RVEDVi for success after PVR; and Lee et al. [47] use RVEDVi $\leq 163 \mathrm{~mL} / \mathrm{m}^{2}$ or RVESVi $\leq 80 \mathrm{~mL} / \mathrm{m}^{2}$. Owing to the high accessibility in patients with prior coils or devices, $3 \mathrm{D}$-echocardiography-derived $\mathrm{RV}$ volume is used after TOF repair. The 3D RV volume correlates well with the CMR reference but shows slight underestimation [48]. In a majority of unselected patients with complex CHD, 3D RV volume showed fair-to-good accuracy compared 


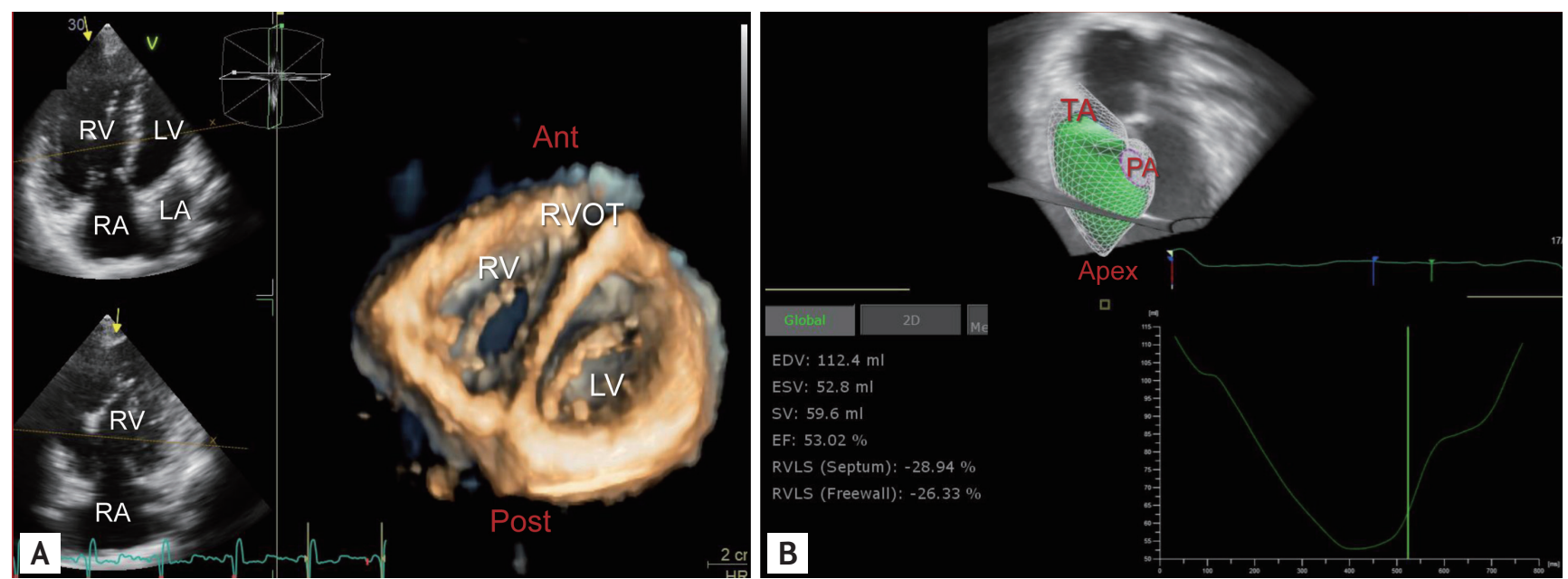

Figure 4. Three-dimensional (3D) transthoracic echocardiography in a patient with repaired tetralogy of Fallot. (A) Enlarged right ventricle (RV) with diastolic flattened inter-ventricular septum in an en face view of the tricuspid valve. (B) Right ventricular volume and 3D or 4D strain was calculated from the $3 \mathrm{D}$ volumetric dataset (GE EchoPAC workstation version 201, GE Healthcare). RA, right atrium; LV, left ventricle; LA, left atrium; RVOT, right ventricular outflow tract; TA, tricuspid annulus; PA, pulmonic annulus; EDV, end-diastolic volume; ESV, end-systolic volume; SV, stroke volume; EF, ejection fraction; RVLS, right ventricular longitudinal strain.

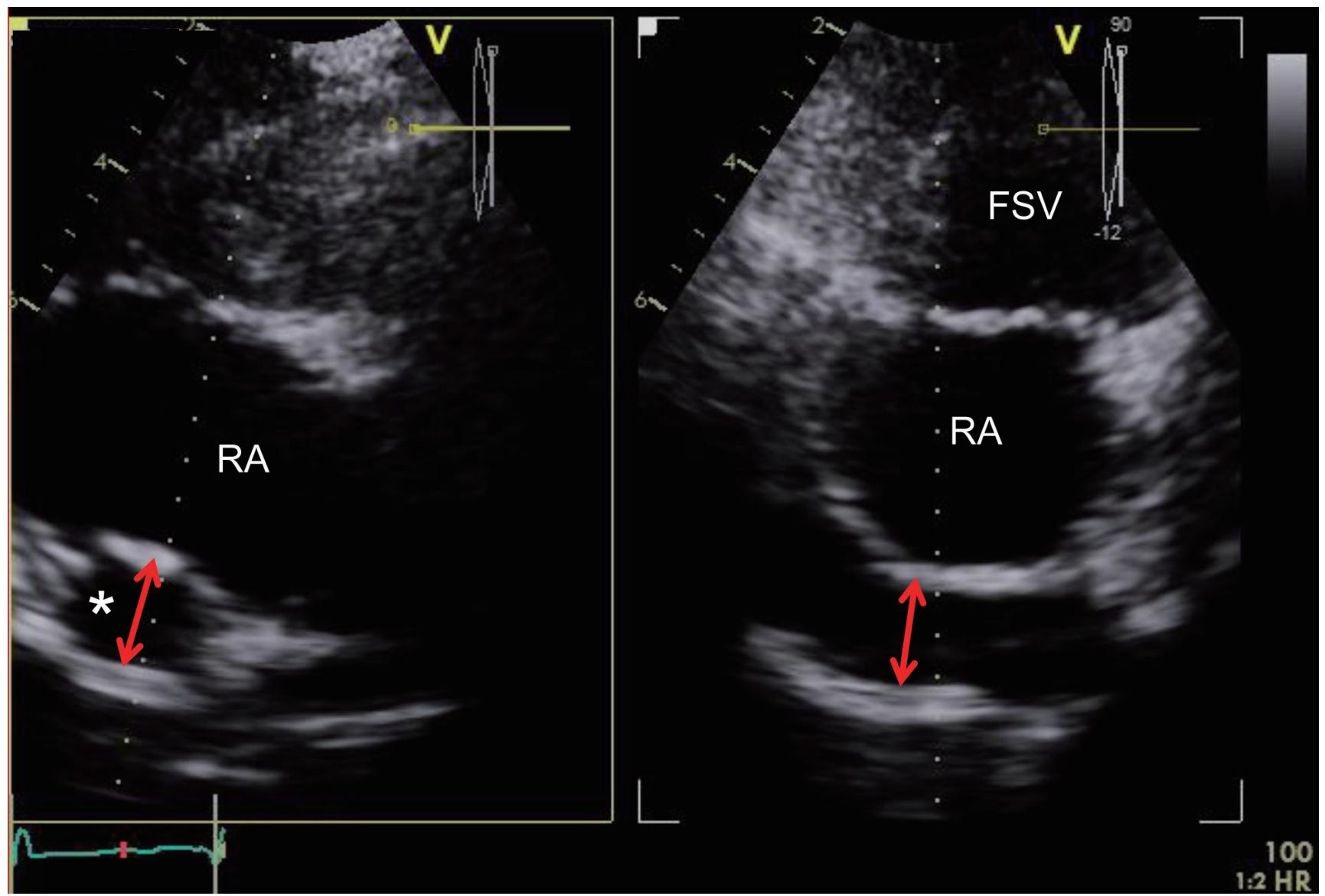

Figure 5. Bi-plane image via three-dimensional (3D) transthoracic echocardiography reveals a patent extracardiac Fontan conduit $\left.{ }^{*}\right)$ without thrombi in the short and long axes simultaneously. RA, right atrium; FSV, functional single ventricle. 
with a CMR reference when using commercially available hardware and software [49], and in a single center study with 25 patients with severe pulmonary regurgitation secondary to either pulmonary valvotomy or TOF repair, 3D RV volume was comparable to magnetic resonance imaging [50]. Particularly for patients with repaired TOF, easily accessible, reliable, repeatable quantification of the $\mathrm{RV}$ by $3 \mathrm{D}$ echo is important to provide appropriate surgical timing to optimize outcomes. Further studies from multiple centers are required to evaluate $3 \mathrm{D}$-echocardiography-derived $\mathrm{RV}$ volume indices for timing the PVR in repaired TOF.

\section{Functional single ventricle}

The term 'single ventricle' may describe not just one literal, anatomic ventricle but a single hemodynamically functional ventricle, where the description includes a variety of complex CHDs such as hypoplastic left heart syndrome, tricuspid atresia, pulmonary atresia with intact ventricular septum, and double-inlet ventricles. Typical FSV presents as only one well-developed ventricle with a rudimentary additional ventricle $<30 \%$ of its normal volume [14]. The Fontan procedure is palliative for complex CHD and not amenable to biventricular repair to direct systemic venous blood and pulmonary circulation bypassing the ventricular mass; the FSV supports only systemic circulation. The most common forms of the Fontan procedure are atriopulmonary connections and the cavopulmonary connection (intra-atrial lateral tunnel, extracardiac conduit) [51]. From a single center study of 1,052 post-Fontan patients, 10-, 20-, and 30 -year survival was reported to be $74 \%, 61 \%$, and $43 \%$, respectively [52]. In adult CHD, patients with FSV are typically post-Fontan patients and follow-up assessment is recommended for long-term post-Fontan complications [52], such as ventricular dysfunction, atrioventricular valve regurgitation, arrhythmia, thromboembolic events, kidney disease, protein-losing enteropathy, and liver disease.

Generally, echocardiographic follow-up for patients with FSV falls into three categories: patency of surgically altered blood flow, single ventricular function, and atrioventricular valve regurgitation (Figs. 5-7). Of these three, quantification of single ventricular size and function remains challenging. Routine $2 \mathrm{D}$ echocardiographic measurements of ventricular cavity dimensions, EF, or myocardial strain are not often used to represent the entire FSV size and function due to the unreliable ven-
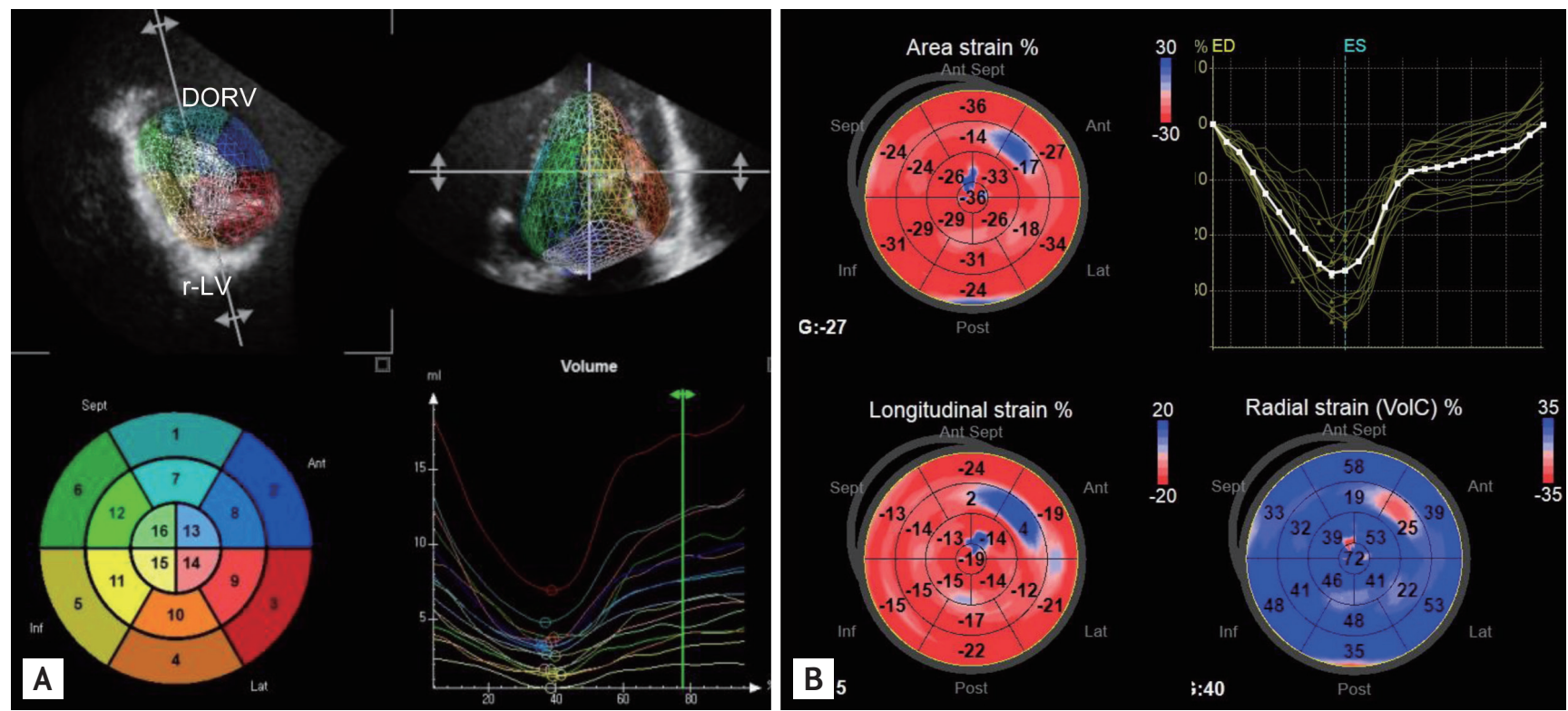

Figure 6. (A, B) A full-volume-dataset rendered functional single ventricular global and regional volumetric information in a patient with right isomerism, functionally single ventricle, and a double-outlet right ventricle (DORV) from three-dimensional (3D) transthoracic echocardiography. Three-dimensional volumetric area strain, longitudinal strain, and radial strain presented in the same patient (GE EchoPAC workstation version 201, GE Healthcare). There is a hypoplastic left ventricle (r-LV) located posteroinferiorly with a good segmental myocardial strain. 

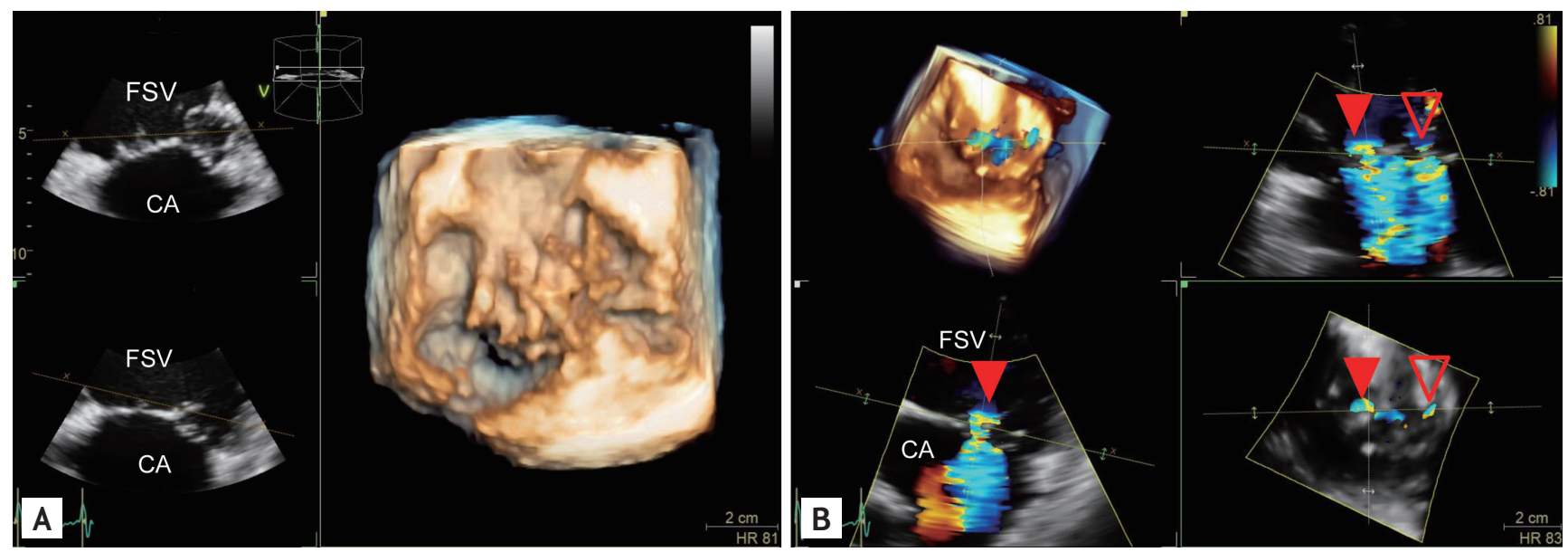

Figure 7. (A) An en face view of a common atrioventricular valve from a ventricular perspective in a 45-year-old woman with left isomerism, a complete atrioventricular septal defect, double-outlet right ventricle, and extracardiac conduit from a Fontan operation. (B) On the three-dimensional (3D) color-Doppler echocardiogram, moderate atrioventricular valve regurgitation (AVVR) is observed: note the major AVVR jet (filled arrowheads) and minor jet (empty arrowheads) across the functional single ventricle (FSV) and common atrium (CA).

tricular geometry and regional myocardial variations, such as a rudimentary ventricle. In clinical practice, the serially followed images of M-mode or 2D tomographic views for ventricular dimensions, EF, or FAC are not consistent and are difficult to compare over intervals. Three-dimensional echocardiography can provide a reliable analysis of the entire FSV and hence is useful for serial, longitudinal follow-up with optimal post-processing of the volumetric raw dataset (Fig. 6). Studies have shown that $3 \mathrm{D}$ echocardiographic measurements of mass and volume are comparable with those obtained by CMR [53], which tend to underestimate LV volumes but show a good correlation of LV volume and EF compared with CMR in patients with FSV [54]. In addition, ventricular torsion by $3 \mathrm{D}$ echo speckle-tracing has been proposed as a novel indicator of single ventricular function [55]. Three-dimensional echocardiography has also been used as a complementary tool for the evaluation of mechanisms and sites of anatomically challenging atrioventricular regurgitation in FSV (Fig. 7) [56].

\section{FUTURE DIRECTIONS}

As methods and clinical tools, 3D ultrasound technologies are innovative, providing a higher resolution and higher volume per second (enough to accommodate a subject in a single beat) along with user-friendly soft- ware and standardized image acquisition and presentation protocols. In the future, $3 \mathrm{D}$ echocardiography is expected to extend its clinical application with $3 \mathrm{D}$ or $4 \mathrm{D}$ strain, myocardial torsion or deformation [57], and intracavitary flow [58], which increases our understanding of the regional or multi-directional myocardial motion and complex flow hemodynamics.

One fundamental issue of $3 \mathrm{D}$ echocardiography is displaying a $3 \mathrm{D}$ image on a conventional $2 \mathrm{D}$ screen; this will improve in the near future with a variety of technologies used to present a genuinely 3D image, as with recent consumer 3D HDTV and virtual reality glasses. Thus, the technique of $3 \mathrm{D}$ imaging is moving from "flatland" to "spaceland" [59]. Similarly, with the advent of 3D printing, $3 \mathrm{D}$ images can be converted to physical ${ }_{3} \mathrm{D}$ models, which will be clinically useful tools for cardiologists and congenital cardiac surgeons for the planning of interventions or surgery [6o,61].

\section{CONCLUSIONS}

A growing number of adult CHD patients with complicated cardiac geometries require additional imaging dimensions in clinical practice. Three-dimensional echocardiography is an important complement to routine 2D echocardiography for adult CHD. Current $3 \mathrm{D}$ echo techniques provide value with an anatomically correct 
plane (en face view of tissue defects or valves) and true volumetric information without geometric assumptions (RV or FSV).

\section{Conflict of interest}

No potential conflict of interest relevant to this article was reported.

\section{Acknowledgments}

Thanks go to Professor Dong-Man Seo, MD, PhD, for the clinical concept of adult congenital heart disease and Min Jung Kang, RN, for the echocardiographic image preparation.

\section{REFERENCES}

1. von Ramm OT, Smith SW. Real time volumetric ultrasound imaging system. J Digit Imaging 1990;3:261-266.

2. Sugeng L, Weinert L, Thiele K, Lang RM. Real-time threedimensional echocardiography using a novel matrix array transducer. Echocardiography 2003;20:623-635.

3. Yang HS, Pellikka PA, McCully RB, et al. Role of biplane and biplane echocardiographically guided 3-dimensional echocardiography during dobutamine stress echocardiography. J Am Soc Echocardiogr 2006;19:1136-1143.

4. Pothineni KR, Inamdar V, Miller AP, et al. Initial experience with live/real time three-dimensional transesophageal echocardiography. Echocardiography 2007;24:10991104.

5. Yang HS, Bansal RC, Mookadam F, et al. Practical guide for three-dimensional transthoracic echocardiography using a fully sampled matrix array transducer. J Am Soc Echocardiogr 2008;21:979-989.

6. Yang HS, Srivathsan K, Wissner E, Chandrasekaran K. Images in cardiovascular medicine. Real-time 3-dimensional transesophageal echocardiography: novel utility in atrial fibrillation ablation with a prosthetic mitral valve. Circulation 2008;117:e304-e305.

7. Dekker DL, Piziali RL, Dong E Jr. A system for ultrasonically imaging the human heart in three dimensions. Comput Biomed Res 1974;7:544-553.

8. Carlgren LE. The incidence of congenital heart disease in children born in Gothenburg 1941-1950. Br Heart J 1959;21:40-50.

9. Hoffman JI, Christianson R. Congenital heart disease in a cohort of 19,502 births with long-term follow-up. Am J Cardiol 1978;42:641-647.

10. Warnes CA, Liberthson R, Danielson GK, et al. Task force 1: the changing profile of congenital heart disease in adult life. J Am Coll Cardiol 2001;37:1170-1175.

11. Shiota T. Role of modern 3D echocardiography in valvular heart disease. Korean J Intern Med 2014;29:685-702.

12. Khoshhal S. Feasibility and effectiveness of three-dimensional echocardiography in diagnosing congenital heart diseases. Pediatr Cardiol 2013;34:1525-1531.

13. Said SM, Driscoll DJ, Dearani JA. Transition of care in congenital heart disease from pediatrics to adulthood. Semin Pediatr Surg 2015;24:69-72.

14. Warnes CA, Williams RG, Bashore TM, et al. ACC/AHA 2008 guidelines for the management of adults with congenital heart disease: a report of the American College of Cardiology/American Heart Association Task Force on Practice Guidelines (Writing Committee to Develop Guidelines on the Management of Adults With Congenital Heart Disease). Developed in Collaboration With the American Society of Echocardiography, Heart Rhythm Society, International Society for Adult Congenital Heart Disease, Society for Cardiovascular Angiography and Interventions, and Society of Thoracic Surgeons. J Am Coll Cardiol 2008;52:e143-e263.

15. Cao Q, Radtke W, Berger F, Zhu W, Hijazi ZM. Transcatheter closure of multiple atrial septal defects: initial results and value of two- and three-dimensional transoesophageal echocardiography. Eur Heart J 2000;21:941-947.

16. Perk G, Lang RM, Garcia-Fernandez MA, et al. Use of real time three-dimensional transesophageal echocardiography in intracardiac catheter based interventions. J Am Soc Echocardiogr 2009;22:865-882.

17. Tobis J, Shenoda M. Percutaneous treatment of patent foramen ovale and atrial septal defects. J Am Coll Cardiol 2012;60:1722-1732.

18. Kong D, Cheng L, Dong L, et al. Three-dimensional echocardiography in the evaluation of right ventricular global and regional systolic function in patients with atrial septal defect before and after percutaneous closure. Echocardiography 2016;33:596-605.

19. Roguin N, Du ZD, Barak M, Nasser N, Hershkowitz S, Milgram E. High prevalence of muscular ventricular septal defect in neonates. J Am Coll Cardiol 1995;26:1545-1548.

20. Mercer-Rosa L, Seliem MA, Fedec A, Rome J, Rychik J, Gaynor JW. Illustration of the additional value of re- 
al-time 3-dimensional echocardiography to conventional transthoracic and transesophageal 2-dimensional echocardiography in imaging muscular ventricular septal defects: does this have any impact on individual patient treatment? J Am Soc Echocardiogr 2006;19:1511-1519.

21. Sivakumar K, Singhi A, Pavithran S. Enface reconstruction of VSD on RV septal surface using real-time ${ }_{3} \mathrm{D}$ echocardiography. JACC Cardiovasc Imaging 2012;5:11761180.

22. Acar P, Abadir S, Aggoun Y. Transcatheter closure of perimembranous ventricular septal defects with Amplatzer occluder assessed by real-time three-dimensional echocardiography. Eur J Echocardiogr 2007;8:110-115.

23. Ahmed MI, Gok G, Yuzbas B, et al. Incremental value of three-dimensional echocardiography over the two-dimensional technique in the assessment of combined sinus of valsalva rupture into the right ventricle and adjacent perimembranous ventricular septal defect. Echocardiography 2014;31:779-782.

24. Chamsi-Pasha MA, Sayyed SH, Moulton MJ. Real-time 3-dimensional transesophageal echocardiography in the assessment of ventriculoatrial shunt (Gerbode defect) complicating simultaneous mitral and tricuspid valve repair. J Am Coll Cardiol 2014;63:e37.

25. Carpentier A, Chauvaud S, Mace L, et al. A new reconstructive operation for Ebstein's anomaly of the tricuspid valve. J Thorac Cardiovasc Surg 1988;96:92-101.

26. Attenhofer Jost CH, Connolly HM, Dearani JA, Edwards WD, Danielson GK. Ebstein's anomaly. Circulation 2007;115:277-285.

27. Badano LP, Agricola E, Perez de Isla L, Gianfagna P, Zamorano JL. Evaluation of the tricuspid valve morphology and function by transthoracic real-time three-dimensional echocardiography. Eur J Echocardiogr 2009;10:477484.

28. Patel V, Nanda NC, Rajdev S, et al. Live/real time three-dimensional transthoracic echocardiographic assessment of Ebstein's anomaly. Echocardiography 2005;22:847-854.

29. van Noord PT, Scohy TV, McGhie J, Bogers AJ. Three-dimensional transesophageal echocardiography in Ebstein's anomaly. Interact Cardiovasc Thorac Surg 2010;10:836837.

30. Negoi RI, Ispas AT, Ghiorghiu I, et al. Complex Ebstein's malformation: defining preoperative cardiac anatomy and function. J Card Surg 2013;28:70-81.

31. Reller MD, Strickland MJ, Riehle-Colarusso T, Mahle WT,
Correa A. Prevalence of congenital heart defects in metropolitan Atlanta, 1998-2005. J Pediatr 2008;153:807-813.

32. O'Leary PW, Edwards WD, Julsrud PR, Puga FJ. Pulmonary atresia and ventricular septal defect. In: Allen HD, Driscoll DJ, Shaddy RE, Feltes TF, eds. Moss and Adams' Heart Disease in Infants, Children and Adolescents. 7th ed. Philadelphia: Lippincott Williams \& Wilkins, 2008:878-887.

33. Al Habib HF, Jacobs JP, Mavroudis C, et al. Contemporary patterns of management of tetralogy of Fallot: data from the Society of Thoracic Surgeons Database. Ann Thorac Surg 2010;90:813-819.

34. Lindberg HL, Saatvedt K, Seem E, Hoel T, Birkeland S. Single-center 50 years' experience with surgical management of tetralogy of Fallot. Eur J Cardiothorac Surg 2011;40:538-542.

35. Valente AM, Cook S, Festa P, et al. Multimodality imaging guidelines for patients with repaired tetralogy of fallot: a report from the American Society of Echocardiography: developed in collaboration with the Society for Cardiovascular Magnetic Resonance and the Society for Pediatric Radiology. J Am Soc Echocardiogr 2014;27:111-141.

36. Rudski LG, Lai WW, Afilalo J, et al. Guidelines for the echocardiographic assessment of the right heart in adults: a report from the American Society of Echocardiography endorsed by the European Association of Echocardiography, a registered branch of the European Society of Cardiology, and the Canadian Society of Echocardiography. J Am Soc Echocardiogr 2010;23:685-713.

37. Larrazet F, Czitrom D, Laborde F, Bouabdallah K, Folliguet T. Decreased right ventricular lateral wall velocities early after cardiac surgery. Echocardiography 2011;28:438-441.

38. Tamborini G, Muratori M, Brusoni D, et al. Is right ventricular systolic function reduced after cardiac surgery? A two- and three-dimensional echocardiographic study. Eur J Echocardiogr 2009;10:630-634.

39. Atsumi A, Seo Y, Ishizu T, et al. Right ventricular deformation analyses using a three-dimensional speckle-tracking echocardiographic system specialized for the right ventricle. J Am Soc Echocardiogr 2016;29:402-411.e2.

40. Ferraz Cavalcanti PE, Sa MP, Santos CA, et al. Pulmonary valve replacement after operative repair of tetralogy of Fallot: meta-analysis and meta-regression of 3,118 patients from 48 studies. J Am Coll Cardiol 2013;62:22272243.

41. Sabate Rotes A, Eidem BW, Connolly HM, et al. Long- 
term follow-up after pulmonary valve replacement in repaired tetralogy of Fallot. Am J Cardiol 2014;114:901-908.

42. Silversides CK, Kiess M, Beauchesne L, et al. Canadian Cardiovascular Society 2009 Consensus Conference on the management of adults with congenital heart disease: outflow tract obstruction, coarctation of the aorta, tetralogy of Fallot, Ebstein anomaly and Marfan's syndrome. Can J Cardiol 2010;26:e8o-e97.

43. Baumgartner H, Bonhoeffer P, De Groot NM, et al. ESC guidelines for the management of grown-up congenital heart disease (new version 2010). Eur Heart J 2010;31:29152957.

44. Therrien J, Provost Y, Merchant N, Williams W, Colman J, Webb G. Optimal timing for pulmonary valve replacement in adults after tetralogy of Fallot repair. Am J Cardiol 2005;95:779-782.

45. Oosterhof T, van Straten A, Vliegen HW, et al. Preoperative thresholds for pulmonary valve replacement in patients with corrected tetralogy of Fallot using cardiovascular magnetic resonance. Circulation 2007;116:545-551.

46. Geva T, Gauvreau K, Powell AJ, et al. Randomized trial of pulmonary valve replacement with and without right ventricular remodeling surgery. Circulation 2010;122(11 Suppl):S201-S208.

47. Lee C, Kim YM, Lee CH, et al. Outcomes of pulmonary valve replacement in 170 patients with chronic pulmonary regurgitation after relief of right ventricular outflow tract obstruction: implications for optimal timing of pulmonary valve replacement. J Am Coll Cardiol 2012;60:1005-1014.

48. Sugeng L, Mor-Avi V, Weinert L, et al. Multimodality comparison of quantitative volumetric analysis of the right ventricle. JACC Cardiovasc Imaging 2010;3:10-18.

49. van der Zwaan HB, Helbing WA, McGhie JS, et al. Clinical value of real-time three-dimensional echocardiography for right ventricular quantification in congenital heart disease: validation with cardiac magnetic resonance imaging. J Am Soc Echocardiogr 2010;23:134-140.

50. Grewal J, Majdalany D, Syed I, Pellikka P, Warnes CA. Three-dimensional echocardiographic assessment of right ventricular volume and function in adult patients with congenital heart disease: comparison with magnetic resonance imaging. J Am Soc Echocardiogr 2010;23:127133 .

51. Katogi T. Extracardiac conduit Fontan procedure versus intra-atrial lateral tunnel Fontan procedure. Gen Thorac
Cardiovasc Surg 2012;60:792-795.

52. Pundi KN, Johnson JN, Dearani JA, et al. 40-Year follow-up after the Fontan operation: long-term outcomes of 1,052 patients. J Am Coll Cardiol 2015;66:1700-1710 .

53. Soriano BD, Hoch M, Ithuralde A, et al. Matrix-array 3-dimensional echocardiographic assessment of volumes, mass, and ejection fraction in young pediatric patients with a functional single ventricle: a comparison study with cardiac magnetic resonance. Circulation 2008;117:1842-1848.

54. Zhong SW, Zhang YQ, Chen LJ, Wang SS, Li WH. Evaluation of left ventricular volumes and function by real time three-dimensional echocardiography in children with functional single left ventricle: a comparison between QLAB and TomTec. Echocardiography 2015;32:1554-1563.

55. Zhong SW, Zhang YQ, Chen LJ, Wang SS, Li WH, Sun YJ. Ventricular twisting and dyssynchrony in children with single left ventricle using three-dimensional speckle tracking imaging after the fontan operation. Echocardiography 2016;33:606-617.

56. Takahashi K, Mackie AS, Rebeyka IM, et al. Two-dimensional versus transthoracic real-time three-dimensional echocardiography in the evaluation of the mechanisms and sites of atrioventricular valve regurgitation in a congenital heart disease population. J Am Soc Echocardiogr 2010;23:726-734.

57. Kaku K, Takeuchi M, Tsang W, et al. Age-related normal range of left ventricular strain and torsion using three-dimensional speckle-tracking echocardiography. J Am Soc Echocardiogr 2014;27:55-64.

58. Gomez A, de Vecchi A, Jantsch M, et al. 4D blood flow reconstruction over the entire ventricle from wall motion and blood velocity derived from ultrasound data. IEEE Trans Med Imaging 2015;34:2298-2308.

59. Deferm S, Meyns B, Vlasselaers D, Budts W. 3D-printing in congenital cardiology: from flatland to spaceland. J Clin Imaging Sci 2016;6:8.

6o. Costello JP, Olivieri LJ, Su L, et al. Incorporating three-dimensional printing into a simulation-based congenital heart disease and critical care training curriculum for resident physicians. Congenit Heart Dis 2015;10:185-190.

61. Gosnell J, Pietila T, Samuel BP, Kurup HK, Haw MP, Vettukattil JJ. Integration of computed tomography and three-dimensional echocardiography for hybrid three-dimensional printing in congenital heart disease. J Digit Imaging 2016;29:665-669. 